\title{
Erratum to: The Interactive Mobile App Review Toolkit (IMART): a Clinical Practice-Oriented System
}

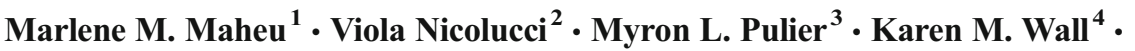 \\ Tami J. Frye ${ }^{5}$ Eva Hudlicka ${ }^{6}$
}

Published online: 1 December 2017

(C) Springer International Publishing AG 2017

Erratum to: J Technol Behav Sci Published Vol 1 Nos 1-4

pp. 3-15

https://doi.org/10.1007/s41347-016-0005-Z

On page 5 the first line in the body of Table 1 should read:

"ASPECTS" of an App (Torous et al., 2016) and the "2016" should be hyperlinked to the corresponding item in the References section:

Torous, J. B., Chan, S. R., Yellowlees, P., \& Borland, R. (2016). To use or not? Evaluating ASPECTS of smartphone apps and mobile technol-ogy for clinical care in psychiatry. Journal of Clinical Psychiatry, 77(6), e734-e738. doi:https:// doi.org/10.4088/JCP.15com10619.

The online version of the original article can be found at 10.1007/s41347$016-0005-\mathrm{z}$

Myron L. Pulier

pulierml@gmail.com

Marlene M. Maheu

mmaheu@telehealth.org

Viola Nicolucci

violanicolucci@gmail.com

Karen M. Wall

logos68540@gmail.com

Tami J. Frye

tami.frye@waldenu.edu

Eva Hudlicka

hudlicka@cs.umass.edu
1 TeleMental Health Institute, Inc., Arizona State University, 5173, Waring Road \#124, San Diego, CA 92120, USA

2 Ordine degli Psicologi del Piemonte, Network Professionale di Alessandria, Alessandria, Italy

3 Rutgers New Jersey Medical School, Newark, NJ, USA

4 Community Living Center, 195 Willow Rd/33-C152, Menlo Park, CA 94025, USA

5 Contributing Faculty, College of Social and Behavioral Sciences, Walden University, 100 Washington Avenue, S. \#900, Minneapolis, MN 55401, USA

6 School of Information and Computer Sciences, University of Massachusetts-Amherst, 140 Governors Dr, Amherst, MA 01003, USA 